\title{
Health challenges in the Golden Land
}

$\mathrm{E}$ merging from the shadows of five decades of military rule, the nation once known as the "Jewel of Asia" is beset by an array of less than illustrious health challenges, including high rates of beri-beri, malaria, HIV/AIDS and tuberculosis (TB). And while Myanmar is initiating reforms at a pace that United States President Barack Obama called "remarkable," those challenges remain acute against a backdrop of widespread malnutrition, especially in rural areas.

It is the only country on the planet where the easily treatable, thiaminedeficiency disease, beri-beri, is still a leading cause of child mortality.

Myanmar is also the country that has been identified as the main AsiaPacific threat in the global fight to contain malaria. A recent study has shown a rise in cases of drug-resistant strains on the Myanmar-Thai border, scene of the world's longest-running civil war between government forces and ethnic Kayin, where access is difficult and medical facilities almost nonexistent (Malaria Journal 2012;11:290).

Papers presented at a regional malaria conference in Sydney, Australia in October 2012, identified poor surveillance, presumptive diagnoses and a health sector that too often issues poor quality, single-drug treatments as obstacles to the treatment of malaria (http://malaria2012conference.com/cms /wp-content/uploads/2012/10/Malaria -2012-Issues-paper-No-3.pdf). The Golden Land was responsible for $70 \%$ of malaria deaths in the Mekong region in 2010.

"Myanmar has received very little support to contain the spread of resistance and is potentially a route for resistant parasites to spread to other regions," according to a paper issued in Sydney (http://malaria2012conference .com/cms/wp-content/uploads/2012/10 /Malaria-2012-Issues-paper-No-4.pdf).

But the nation is aiming to ramp up testing and switch to artemisinin-based combination therapy, says Dr. Saw Lwin, deputy director general of the Myanmar Department of Health. With still only $65 \%$ of malaria cases confirmed and just $10 \%$ of the country's roughly 49 million people, living in a $676578 \mathrm{~km}^{2}$ area, covered by durable, insecticide-sprayed mosquito nets, "all implementing partners are scaling up case-finding activities and distribution of ... nets," he says.

Myanmar's HIV/AIDS epidemic is similarly urgent. Although incidence peaked around the turn of the millennium and is falling, that's primarily due to a woefully high mortality rate. By

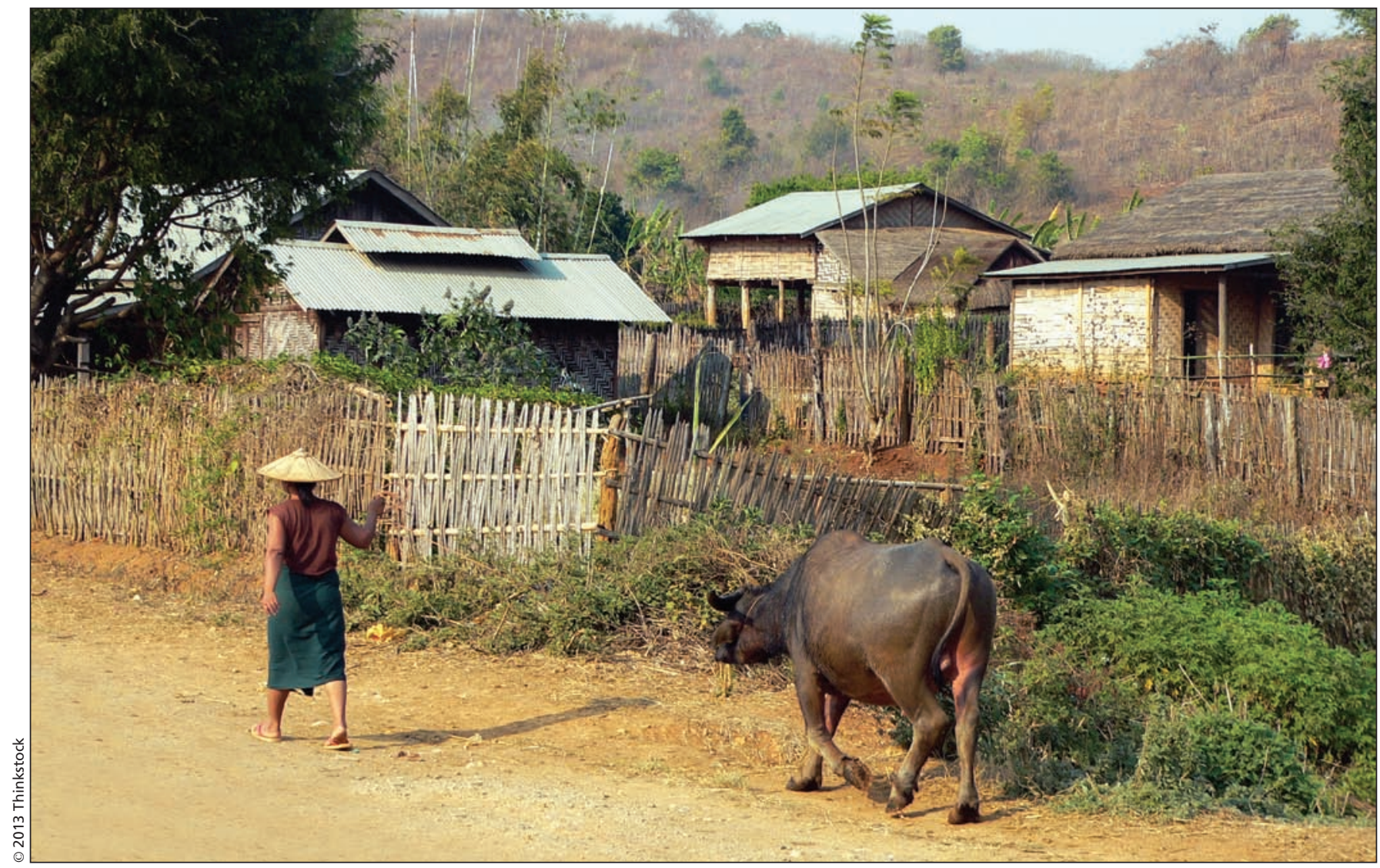

In some areas of Myanmar, access to health facilities is all but nonexistent. 
2013, fewer than 200000 people in Myanmar will be HIV-positive, versus about 210000 a year ago. But that's due to the deaths of an estimated 18000 people, the majority of whom died from AIDS-related TB. Over the same period, roughly 8300 new cases of AIDS among people over the age of 15 were diagnosed, according to a working group comprised of United Nations and Myanmar Department of Health officials (www.hivinfo4mm.org /wordpress/wp-content/uploads/myanmar -hiv-estimates1.pdf).

The high AIDS mortality rate is strictly a function of the low provision rate for antiretrovirals. Only about 40000 of the estimated 125000 people in need of treatment in 2011 received antiretrovirals, according to UNAIDS, a lower percentage than Mozambique and about the same as neighbouring India (www.unaids.org/en /media/unaids/contentassets/documents /epidemiology/2012/gr2012/20121120 _UNAIDS_Global_Report_2012_en.pdf).

"This practically means that two out of three people that needed HIV/AIDS treatment were not receiving it," Peter Paul de Groote, head of the Dutch chapter of the international medical relief agency Médecins Sans Frontières (MSF) in Myanmar, said at the opening of a new TB/HIV outpatient centre in Yangon in December 2012.

Duncan Bell, head of mission at the Swiss chapter of MSF, says that although the widely accepted time to start antiretroviral treatment is after a CD4 count falls to 350, that does not happen often in Myanmar.

Treatment did not begin for the roughly 20000 people that MSF provided antiretrovirals to in 2011 until they had CD4 counts of 150 or lower, Bell says. "This is simply due to a lack of funding."

Myanmar ranks close to the bottom among the 22 TB high-burden countries on testing labs per capita, according to the World Health Organization. In 2011, Myanmar administered HIV tests to just $3.1 \%$ of TB patients, all of whom were started on cotrimoxazole preventive therapy but only $80 \%$ of whom received antiretrovirals.

But Bell says the problems extend well beyond the availability of financial resources and points to headaches that resulted when MSF sought to open one of four new TB/HIV centres in Yangon. Stigmatization meant landlords were unwilling to rent out land or buildings for the clinic, forcing Minister of Health Dr. Pe Thet Khin to intervene and allow MSF to establish it on the grounds of a state hospital. Even then, managers tried to block the move.

It was eventually opened and is now the first such facility located within a Myanmar ministry facility, says Bell. It's a sign of capacity problems and a lack of cooperation that stems from decades of military rule, he notes, adding that such issues suggest Myanmar's health system will take substantial time to improve. "Yes, there is reform but let's not get euphoric yet." - Steve Finch, Yangon, Myanmar

CMAJ 2013. DOI:10.1503/cmaj.109-4368 